\title{
Diseño institucional y neoliberalismo. El modelo chileno como resultado del quiebre unilateral del contrato social*
}

\author{
Francisco Báez Urbina \\ Universidad de Playa Ancha. Valparaíso (Chile) \\ francisco.baez@upla.cl
}

Recepción: 04-03-2016

Aceptación: 26-09-2016

\section{Resumen}

El presente artículo intenta definir el sentido de los procesos de rediseño institucional ocurridos sobre la sociedad chilena en los últimos treinta años, basados en lo que denominamos descolectivización y que han sido operados sobre lo constitucional, la propiedad estatal y el funcionamiento de la economía privada. Sostenemos que el problema de la descolectivización en Chile proviene del rompimiento unilateral del contrato social entre clases ocurrido a mediados de la década de 1970. Como recurso metodológico, se expone el contrato social, mecanismo institucional previsto para corregir la tensión entre intereses individuales y resultados sociales, y la figura del forced rider, o consumidor forzado de bienes públicos. Esto, con el fin de intentar ilustrar las restricciones y la contención de beneficios que la matriz sociopolítica desarrollista - el modelo de capitalismo embridado o reformado - imponía sobre el capital entre las décadas de 1940 y 1970, lo que provocó que la élite rompiera unilateralmente con el contrato democrático y generó las condiciones para imponer un nuevo diseño institucional, esta vez más restrictivo y antidemocrático. Como resultado y discusión, se exponen sucintamente una serie de consecuencias observables que el diseño institucional neoliberal habría comportado, tanto en el terreno político como en el económico y cultural. Todas son consecuencias que vienen a confirmar las conjeturas teóricas que sostienen que el rediseño institucional neoliberal significa un proyecto de clase que viene a destruir los logros del proyecto político de la alianza de las clases medias y bajas propios del desarrollismo nacional popular.

Palabras clave: neoliberalismo; acción colectiva; democracia; desigualdad; políticas públicas; Chile

* Artículo producto del proyecto FONDECYT de Iniciación en Investigación, año 2013, n. ${ }^{\circ} 11130026$. 
Abstract. Institutional Design and Neoliberalism: The Chilean Model as a Result of the Unilateral Break of the Social Contract

This article aims to define the meaning of institutional redesign processes in Chilean society over the last 30 years, which were based on the so-called de-collectivisation operating over the constitution, public property and the private economy. We argue that the de-collectivisation problem in Chile was a consequence of the unilateral break-up between social classes of the mid-1970s. In methodological terms, we present the social contract as an institutional mechanism to correct tensions between individual interests, its social results and the so-called forced rider, a forced consumer of public goods. This explanation of social contract allows us to illustrate the restrictions and benefit containment that the development-based, socio-political matrix imposed on capital from the 1940s to the 1970s, which led to the unilateral break-up of the democratic contract and opened the doors for a more restrictive and even new, anti-democratic institutional design. As a result, we briefly present the observable consequences that neoliberal institutional design has brought into the political, economic and cultural arenas. All of these consequences confirm the theoretical hypothesis that neoliberal institutional redesign was a class project that destroyed the achievements of the developmental political project based on the alliance between the middle and lower classes.

Keywords: neoliberalism; collective action; democracy; inequity; public policy; Chile

\section{Sumario}

\section{Introducción}

2. La élite y el quiebre unilateral del pacto social desarrollista

3. El contrato como mecanismo de solución al problema de la acción colectiva mediante cooperación forzada
4. El metadiseño institucional implantado: las bases de la institucionalidad

5. Reflexiones finales

Referencias bibliográficas

\section{Introducción}

El presente artículo intenta definir el sentido de los procesos de rediseño institucional ocurridos sobre la sociedad chilena basados en la descolectivización y operados sobre lo constitucional, la propiedad estatal y el funcionamiento de la economía privada. Desde el enfoque de la teoría social analítica, sostenemos que el problema de la descolectivización en Chile proviene del rompimiento unilateral del contrato social entre clases ocurrido a mediados de la década de 1970, y que ello habría comportado una serie de consecuencias observables, tanto en el terreno político como en el económico y cultural. Dicho rompimiento, que desde los estudios de la acción colectiva y el diseño institucional entendemos como un problema de cooperación basado en un juego bilateral de cooperación condicional entre clases o sectores sociales determinados (entre capital y trabajo), habría traído consigo el vaciamiento político, la despolitización de la esfera económica y la social, así como la caída de la actividad colec- 
tiva como forma relevante de acción social. Todo esto además de resultados socioeconómicos de éxito relativo para las diferentes categorías socioeconómicas, es decir, resultados de altísimos beneficios agregados para algunos sectores sociales respecto de otros, a saber, la élite oligopólico-financiera respecto de vastos sectores tercerizados, desprotegidos y precarizados de la economía nacional.

En ese sentido, desde una perspectiva amplia, sostenemos que los diversos procesos de descolectivización (desmantelamiento unilateral del contrato interclases keynesiano) constitucional ${ }^{1}$, organizacional ${ }^{2}$ e institucional ${ }^{3}$ puestos en operación en Chile desde el Estado y desde mediados de la década de 1970 hasta la fecha ${ }^{4}$, han incidido profundamente en la manera cómo nos relacionamos como agentes con el Estado y con los demás en la esfera pública, cómo nos relacionamos como agentes dentro de la esfera económica y cómo nos relacionamos como sujetos dentro de la esfera sociocultural. Esto es, cómo el diseño institucional en general, es decir, las metarreglas del juego constitucional y la estructura institucional nos han ido llevando a cierto tipo de creencias y de comportamientos en lo público y en lo privado, situación que actualmente puede dar cuenta de la asimetría observada en cuanto a los logros políticos y económicos favorables y desfavorables obtenidos por unos y por otros.

En lo que sigue, plantearemos el problema del quiebre unilateral del pacto social desarrollista por parte de la élite chilena a comienzos de los años setenta, centrándonos en sus causas y en el contexto internacional donde tiene cabida. Para ello, utilizamos la categoría de diseño institucional de Philip Pettit (2003), la óptica aportada por Elster (1989) sobre el problema de la acción colectiva en su versión estándar, además de la noción de acumulación por desposesión de David Harvey $(2003$, 2007). A continuación, abordamos sucintamente el problema de la acción colectiva desde una perspectiva analítica, basándonos en sus formas centralizadas de resolución, esto es, la acción colectiva organizada socialmente. En esa dirección, detallamos la noción de contrato social en Schelling (1989), señalando algunas implicaciones de la aplicación del contrato. Seguidamente, nos referiremos al modelo institucional implementado tras el rompimiento de dicho pacto, para luego cerrar con algunos comentarios finales.

\section{La élite y el quiebre unilateral del pacto social desarrollista}

Como se ha venido sosteniendo desde la reflexión académica, nos encontramos en el peor período de desigualdad económica en la historia moderna republicana (Chomsky, 2010; Harvey, 2007). Actualmente, no se dispone de suficiente democracia en la esfera económica, en circunstancias en que una democracia económica (equidad material), incluso más que la propia democracia política, baluarte por definición de las libertades modernas liberales, es

1. Metaestructura de las reglas del juego a escala nacional.

2. Estructura de la Administración estatal.

3. Estructura de incentivo individual y psicología política individualista que promueve.

4. Bajo el argumento de la eficiencia técnico-económica. 
la precondición necesaria y básica para la producción de escenarios de desarrollo de una vida buena y justa (Gargarella, 1999; Habermas y Rawls, 1998; Klein, 2010; Kucinich, 2010; Pettit, 2003; Piketty, 2014; Polanyi, 2003). En ese sentido, considerando la evolución reciente de la economía mundial y los eventos en proceso en la economía norteamericana y europea del año 2008 a esta parte, que relacionan el aumento de las cifras de desigualdad global y subnacional —explicadas por un estancamiento relativo (o, incluso, un retroceso) de los resultados o de los beneficios sociales de las clases medias y de las medias bajas en los últimos treinta años respecto de los sectores sociales poseedores de capital — 5 con la instauración de mecanismos de desmantelamiento de la institucionalidad social construida a partir de los consensos de postguerra ${ }^{6}$ basados en la promoción de la libertad individual respecto de los derechos colectivos (Casassas, 2010; Castel, 2010, 2013; Castel et al., 2013; Domènech y Raventós, 2010; Gargarella, 2014; Harvey, 2003, 2007; Hoexter, 2013; Kwame Sundaram y Popov, 2013; Pisarello, 2011), creemos necesario volver a analizar los procesos de desmontaje del capitalismo regulado u organizado y sus consecuencias sociales en Chile, pero esta vez desde la sociología analítica, desde los problemas de la acción colectiva previstos en ella y desde una economía política de inspiración republicana. Esto considerando que una buena parte de las actuales hipótesis sobre el comportamiento actual de la economía mundial señala que las causas de la crisis actual se vinculan directamente con los fenómenos de desregulación económica, que los orígenes de tal desmontaje (de la receta global) fueron probados en Chile entre mediados de la década de 1970 y fines de la de 1980 (lo que nos convierte en conocedores experimentados, tanto de la naturaleza como de los efectos de dichos procesos de desmontaje $)^{7}$, y que, cuarenta años después, en medio de un proceso en marcha de reactivación de la acción colectiva contenciosa en el país, dichos procesos adquieren una significación histórico-política mucho más específica e informativa que en medio de la transición a la democracia, sobre todo en lo referido tanto a las consecuencias del rediseño institucional como a las consideraciones de justicia distributiva relacionadas (modos justos que se utilizan para la asignación de bienes) y que hoy pueblan todos los debates interesantes sobre la calidad de la democracia y de las instituciones políticas y económicas.

Desde el vínculo entre neorrepublicanismo y sociología analítica, entendemos como diseño institucional $-\mathrm{O}$ «metadiseño institucional»— al conjunto de las «intervenciones en todos los acuerdos que coordinan la conducta de los individuos dentro de la sociedad [...] Incluyen los procedimientos establecidos

5. Medidos en salarios reales, por ejemplo.

6. Que entendemos como la disolución del contrato y que incluyen los actuales intentos de desmantelamiento posterior a la crisis subprime del estado social europeo, como los casos de Grecia y España, por ejemplo, o los mal llamados países PIIG.

7. Producto de la aplicación temprana de los supuestos doctrinarios conservadores en materia económica (el monetarismo de Chicago), el modelo político y económico chileno se apartó prematuramente del modelo populista respecto de otros países de la región y del mundo. 
a nivel constitucional o legalmente, pero también abarcan cuestiones que están apenas sujetas a normas y a convenciones o que están fijadas únicamente por presiones y perspectivas tácitas o registradas acaso ocasionalmente» (Pettit, 2003). Estas nociones están basadas en, al menos, tres supuestos comportamentales básicos: 1) la conducta en sociedad es sensible a oportunidades y a incentivos disponibles en ciertas situaciones de intercambio entre agentes; 2) dichas estructuras de oportunidades pueden ser modificadas externamente, de manera tal que se pueden obtener resultados agregados determinados - esperados o no-, y 3) existen ciertos criterios que pueden servir para evaluar si algunos patrones agregados de conducta son más deseables que otros, dado lo cual puede resultar más atractivo promoverlos frente a otras alternativas o líneas de acción. Es decir, y posicionándose dentro del republicanismo académico, la conducta puede perfeccionarse, orientarse y promoverse desde ciertos criterios producidos en el interior del juego social y la disputa política. Así, las instituciones, o los resultados persistentes, son producto de la correlación de fuerzas propia de un escenario político determinado y expresan hegemonías sociales y culturales específicas. Esto es, el poder. Por su parte, si el metadiseño consiste básicamente en la creación de un esquema o de una forma determinada de promover ciertos resultados valiosos y no otros, entendemos como rediseño institucional al conjunto de procesos de reorganización de las reglas del juego y de estructura de incentivos que reencamine la obtención de ciertos resultados económicos y sociales y no de otros. A veces incluye el recambio de los grupos que ejercen la hegemonía sociocultural, política y económica en un contexto de intercambio específico (Peters, 2003; Pettit, 2003). Dicho proceso de rediseño, que buscó un heterogéneo y general proceso de descolectivización y desuniversalización de los derechos intencionalmente promovido desde el Estado, involucró el desmantelamiento de lo que se conoció como el capitalismo organizado o contrarreformado del segundo tercio del siglo $\mathrm{xx}^{8}$. Dentro de ello, y concretamente en nuestro caso de estudio, encontramos el protoestado social chileno. Sostenemos que dicho proceso se ha desarrollado por medio de diferentes etapas institucionales relacionadas, las cuales serían:

- La descolectivización organizacional pública (estructura de la Administración estatal).

- La descolectivización constitucional (la estructura de las reglas del juego a escala nacional).

- Lo que, desde la sociología analítica, se define como lo institucional propiamente y que (para fines metodológicos) asociamos a la psicología política que hay detrás. Por tanto, a «lo cultural» o a la convergencia de expectativas: el fomento o el incentivo de motivaciones utilitaristas de primer orden, a la no cooperación en la provisión de bienes públicos (en adelante, BP. Schelling, 1989; Elster, 1989, 1995, 2010).

8. Imperativo liberal contra el Estado social. Según ello, una matriz estadocéntrica es esencialmente poco productiva, ineficiente y eminentemente inflacionaria. 
Es decir, el derrumbamiento de la orientación universalista de los BP producidos por el Estado, la caída de la identidad colectiva referida a lo nacional y el desprestigio observado de la actividad colectiva como forma relevante de acción social, entre otros fenómenos asociados.

Consideramos el problema de la descolectivización como el problema del quiebre reactivo y unilateral del contrato social entre clases por parte de la élite económica. Esto es, el problema de la no cooperación de los agentes corporados de clase que representan a los intereses del capital, respecto a los agentes corporados de clase que representan a los intereses del mundo del trabajo. Dicha situación, que se posibilitó solo sobre la base de la caída inducida de la actividad colectiva popular y de clase media como forma relevante de acción social, y del vaciamiento y la despolitización de la esfera social y económica, habría generado, como consecuencia, la ya referida importante diferenciación en los resultados socioeconómicos obtenidos por los diferentes grupos sociales de la población. La desigualdad económica es producto de la desigualdad política. Entendemos dicho quiebre reactivo y unilateral como el rompimiento del esquema bilateral de cooperación condicional entre clases o sectores sociales determinados, esto es, entre capital y trabajo. Todo ello en la búsqueda de un rediseño cuya finalidad no fuera otra que la de cambiar las reglas del juego para hacer que el resultado de la actividad económica nacional dejara de ser considerado un BP y pasara a ser considerado un conjunto de bienes de orden excluyente, bienes privados del cual poder excluir a la clase trabajadora (Elster, 1989: 248). Dejaron de financiar la sociedad, dejaron de contribuir con las instituciones que aseguraban los derechos económicos y sociales de las mayorías y crearon las condiciones para, en un nuevo esquema, apropiarse privadamente de los resultados generados por la nueva economía configurada. Es decir, el rompimiento unilateral del contrato (golpe de Estado de 1973 y neoliberalización de la sociedad chilena posterior a 1980) implicó la desarticulación del compromiso de clases de la postguerra y las certezas y los logros conseguidos por el movimiento social obrero, lo que implicó la privatización y la pérdida de patrimonio colectivo (propiedad pública), la desarticulación violenta de la acción colectiva popular de clase (destrucción de la organización social y obrera) y la revolución cultural neoconservadora a nivel de psicología política (legitimación simbólica). Al respecto, creemos que «Una sociedad está en equilibrio cuando las actitudes — creencias y aspiraciones- generadas por sus instituciones se sostienen mutuamente y sostienen a esas mismas instituciones» (Elster, 1995: 116).

En relación con ello, definimos descolectivización como el proceso de desinstalación de las regulaciones colectivas y universalistas propias de la modernidad organizada del segundo y del tercer cuarto del siglo xx (el capitalismo organizado o reformado) que aseguraban ciertas protecciones y mecanismos de retribución de los resultados sociales y económicos logrados en términos macro9: los derechos económicos y sociales (Castel, 2010, 2013; Castel

9. Y que involucran importantes conquistas del movimiento obrero propio del siglo xx. 
et al., 2013; Domènech y Raventós, 2010; Domènech, 2013a y 2013b; Harvey, 2007; Rosen, 2010. Esto es, el complejo conjunto de procesos constitucionales (las reglas legales del juego), organizacionales (racionalización y privatización de activos públicos) e institucionales (la reestructuración de los incentivos a nivel individual, la psicología política) promovidos desde el Estado y que han provocado como resultado inducido en la población tanto el repliegue al mundo de lo privado (la desvalorización o pérdida del sentido de lo colectivo como instrumento de consecución de fines relevantes) como consecuencias económicas y sociales regresivas desde el punto de vista del desarrollo social y la equidad distributiva. Así, creemos que el problema de la descolectivización está fuertemente asociado al problema de la privatización de los recursos del Estado, al de la desuniversalización de la estructura institucional protectora, pero también, complementariamente, a la psicología política de la población: la cuestión subjetiva. En ese sentido, nos servimos del concepto de acumulación por desposesión propuesto y desarrollado por Harvey $(2003$, 2007). Por este, entendemos el amplio conjunto de procesos de privatización, desnacionalización, mercantilización de la sociedad y de financierización de la economía que ha estado afectando a la sociedad contemporánea desde mediados de los años setenta y que funciona como línea de continuidad con los procesos similares que describe Marx para la naciente economía industrial capitalista bajo su categoría de acumulación primitiva $\mathrm{u}$ originaria.

Harvey entiende por acumulación por desposesión el amplio, complejo y profundo conjunto de procesos de privatización, de desmantelamiento de derechos universales, desnacionalización, precarización y trasferencia de riqueza bottom up (de abajo hacia arriba) vividos por la población de las clases media y baja iniciados a mediados de la década de 1970, a beneficio de la élite financiera, y que continúa hasta el día de hoy. Así, y para efectos de este escrito, suscribimos la hipotesis de Harvey $(2003$, 2007), que señala que todas las características propias de la acumulación originaria señalada por Marx siguen poderosamente presentes en los procesos de desinstalación de las regulaciones institucionales universalistas, desarrollistas y/o nacionalpopulares (Domènech, 2013a). En ese sentido, queremos argumentar a favor de la idea de que el contrato, como mecanismo centralizado de resolución del problema de la acción colectiva, ilustra de manera apropiada el modelo de cooperación forzada y la restricción institucional que frenó la acumulación de capital entre las décadas de 1950 y de 1970. En nuestro caso, se trata de un juego de confianza entre dos jugadores en el que los compromisos de ambas partes (o de una de ellas, depende de la perspectiva) ${ }^{10}$ dejan de ser creíbles en un momento determinado, y un jugador - anticipando la no cooperación del otro en una ronda futura- opta preventivamente por la no cooperación (cfr. el dilema del prisionero

10. El trabajo entendía que el programa de Allende era un avance histórico en sus reivindicaciones; el capital lo entendió como un rompimiento del acuerdo por parte del mundo popular. 
iterado en Axelrod, $1986^{11}$. Había que destrabar el libre flujo de capitales y la acumulación dineraria. La restricción, el contrato, el pacto de clases entre capital y trabajo conseguido con luchas sociales a nivel mundial, lo colectivo, frenaban el proceso de acumulación. En términos corporados, para la élite era preciso dejar de cooperar con el BP que representaba la contribución a la idea del proyecto nacional y pasar a la no cooperación unilateral. La cooperación forzada del capital frenaba la velocidad, la agilidad.

\section{El contrato como mecanismo de solución al problema de la acción colectiva mediante cooperación forzada}

Por definición, una acción colectiva es una acción emprendida por dos o más agentes (individuales o corporados) que, bajo el ánimo de procurarse beneficios a compartir o no, logran establecer y coordinar esfuerzos comunes (Bowles, 2004; Elster, 2010). Pueden haber expectativas de beneficio común o no. También puede haber ánimo de cooperación para obtener un beneficio unilateral. Por el contrario, un problema de acción colectiva estándar (explicado formalmente a través del dilema del prisionero simple para dos personas uniformes que, en términos utilitaristas, deciden no cooperar con el resto) se dará cuando, debido a que los agentes racionales carecen de incentivos para procurar la consecución de un BP o de un uso colectivo universal, no cooperan actuando con base a motivaciones orientadas al beneficio propio y en detrimento de resultados sociales deseables (Elster, 2010; Olson, 1992; Ostrom, 2000) ${ }^{12}$. En escenarios descentralizados (en ausencia de relaciones de parentesco y de autoridad central), dicho problema suele resolverse mediante una secuencia virtuosa de motivaciones individuales a la acción colectiva: utilitaristas, altruistas psicológicas, altruistas morales, etc. (Elster, 2010). En escenarios centralizados, se resolverá mediante la acción de algún agente externo o de algún principio de autoridad supraindividual que decide por el colectivo de forma vinculante. Si la primera puede entenderse dentro de un orden ideal espontáneo, la segunda solo podrá ser entendida desde la necesidad de un orden instituido que presuponga algún tipo de diseño institucional (Bowles, 2004).

Pues bien, si planteamos que el modelo implantado en Chile después de 1979 es el resultado consecuente del rompimiento unilateral del contrato social entre clases (cuestión que recuerda la estructura típica del juego del seguro ${ }^{13} \mathrm{o}$ la del juego de la confianza con cooperación mutua inicial pero con defección

11. Lo más probable es que haya muchos otros jugadores, pero como la modernidad industrial se organizó teniendo en cuenta que el «otro relevante» respecto del capital era únicamente el mundo del trabajo, y como el texto esta organizado a partir de ello, es decir, a partir de la disputa estructural moderna entre capital y trabajo, solo se considera al otro jugador como el actor trabajo.

12. Aunque también se pueden dar los casos de cooperación de maximizadores utilitaristas por expectativas de reciprocidad futura (la sombra del futuro de Axelrod) o por beneficio medio (la masa crítica de Schelling o de Granovetter).

13. La lógica prevista es: coopero solo si el otro también lo hace. 
unilateral posterior) $-\mathrm{y}$ que dicho rompimiento reactivo y unilateral lo podemos entender como un problema de no cooperación entre clases o sectores sociales corporados determinados-, rescataremos acá un modelo de mecanismo institucional —el contrato social— que ilustra la idea de la constricción de las pulsiones maximizadoras de primer orden orientadas a la maximización excluyente, tanto por parte del capital como del trabajo, es decir, que refleje la idea de la restricción de los intereses de sectores sociales determinados en un escenario de intercambio concreto: el compromiso de clases. Que ilustre la idea de que se pasó de una situación de intercambio en donde - mediante la instauración de un contrato restrictivo y del respeto por él- ambos agentes renunciaban a la no cooperación unilateral obteniendo resultados menores a los esperados, pero obteniendo resultados al fín, a una situación de intercambio en donde una de las partes decide, unilateral y reactivamente, dejar de cooperar y abandonar la restricción vinculante acusando a la otra parte de romper el pacto. Esto bajo el supuesto metodológico de que podemos realizar un análisis de fenómenos políticos estableciendo cierta correspondencia entre comportamiento individual y comportamiento agregado, entre los niveles micro y macro (Coleman, 2011). Es decir: 1) los agregados sociales, los agentes corporados y los actores sociales son el resultado agregado de agentes intencionales con capacidad de agencia que, desde el punto de vista de las motivaciones estándar, se comportan de manera egocentrada, maximizadora; 2) de acuerdo con la correspondencia micro y macro, estos se comportan tal como lo hacen los agentes individuales, esto es, racionalmente, y 3) con ellos, podemos simular teóricamente situaciones determinadas de intercambio a nivel macro (Elster, 1989).

A continuación, abordaremos entonces un modelo analítico destinado a generar BP restringiendo la racionalidad individual maximizadora, tanto del capital como del trabajo (la compulsión a optar por lo preferido, esto es, no cooperar). Dicho modelo, que generará como externalidad la provisión o el consumo forzado de BP, orientará institucionalmente la presión de los resultados de la maximización individual por encima de la racionalidad colectiva, generando outputs sociales medianamente óptimos: el contrato social ${ }^{14}$.

\subsection{El contrato como solución a los fallos de coordinación y a la tensión entre racionalidad individual e irracionalidad colectiva}

Desde el punto de vista analítico, el contrato social es un interesante recurso analítico llamado a ajustar la pulsión individual maximizadora excluyente, logrando, en base a cooperadción impuesta institucionalmente (lo que llamamos «la acción colectiva organizada socialmente»), resultados sociales media-

14. Al igual que los incentivos selectivos de Olson, la masa crítica del propio Schelling o la sombra del futuro de Axelrod, dicho mecanismo es una forma institucional (multipersonal) de gestionar la no cooperación de carácter externo que, recurriendo a las propias bases comportamentales del modelo teórico-económico estándar, agrega complejidad política a la gestión de la no cooperación. 
namente eficientes ${ }^{15}$. Efectivamente, en la senda de la tradición que rescata la idea del contrato ${ }^{16}$, Schelling (1989) relevará la necesidad de generar grandes esfuerzos de organización social de carácter institucional que reestructuren los incentivos, de manera tal que, haciendo lo contrario a lo que sus pulsiones le indican, la gente opte por cooperar restringiéndose dentro de las cláusulas un contrato obligatorio. En esa línea, Schelling muestra que los problemas de irracionalidad colectiva ${ }^{17}$ tienen soluciones y que, en buena medida, estas dependen de la organización social, sea cual sea su modalidad: elaborada o espontánea, permanente o ad hoc, voluntaria o disciplinada, centralizada o descentralizada, a cargo de algunos o a cargo de todos. En este contexto, se pueden obtener mejores resultados colectivos si los beneficiarios del bien fueran restringidos por algún tipo de contrato o convenio multipersonal, y ello aunque dicha restricción no resulte conveniente a nadie desde el punto de vista particular. De no hacerlo, si bien se ahorrará el coste individual de la cooperación, tendrá que estar igualmente dispuesto a provocar consecuencias colectivas insospechadamente graves que, en definitiva, deberían redundar en la caída de los propios beneficios individuales considerados a largo o a medio plazo. Planteada así la situación, Schelling acaba apuntando la necesidad de la política como requerimiento del equilibrio y la coordinación de los intereses del universo. Un planteamiento que, en sí mismo, constituye una profunda crítica al modelo neoclásico estándar (modelo walrasiano o de equilibrio general), programa que tradicionalmente se ha inhibido de toda consideración política en su formalización (Bowles, 2004), por lo menos en su versión ortodoxa. A este respecto, y como señala North: «[...] la organización o constitución política moldea de manera significativa el rendimiento de la economía porque define y hace cumplir las normas económicas» (North en Williamson, 2001). Como sabemos, buena parte de la organización social, sino toda, constará de acuerdos institucionales vinculantes llamados a superar las divergencias o los fallos de coordinación entre el interés individual y el colectivo. No obstante, mientras algunos lo harán con éxito rotundo (colectivos selectivos, asociaciones de inte-

15. La versión bipersonal y para una sola jugada del dilema del prisionero (DPS) constituye un paradigma para graficar situaciones en las que la búsqueda del interés propio lleva a producir resultados colectivos catastróficos. Otras versiones son el dilema del prisionero múltiple (DPM), de Schelling, modelo también trabajado por Granovetter, y el Tit for tat propuesto por Axelrod (1986).

16. El contractualismo clásico de Locke, Hobbes y Rousseau, así como el contractualismo contemporáneo de Habermas y Rawls, por ejemplo. O el neoinstitucionalismo de Coase, la nueva economía institucional de Matthews, la economía del derecho o de los costes de transacción de Williamson, la economía política constitucional de Buchanan, la economía política radical de Bowles o la nueva historia económica de North, dentro de la ciencia económíca institucional.

17. Los comunes de Hardin (1968) fundamentan de muy buena forma la necesidad de constreñir institucionalmente los intereses individuales. Dado el dispendioso empleo impuesto sistemáticamente por todos a recursos comunes de naturaleza escasa, fundamentan la necesidad de que la gente admita someterse voluntariamente a restricciones de carácter individual en función del interés general. 
reses, etc.), otros solo lo lograrán con éxito relativo (mercados, gobiernos, etc.). Mientras algunos serán de naturaleza pública estatal (esfera gubernamental) o pública no estatal (esfera social o de los acuerdos sin fines de lucro entre personas privadas), otros serán de naturaleza mercantil (acuerdos con fines de lucro entre personas privadas). Pero si responder a los fallos de coordinación mediante un contrato puede concebirse como una forma de dar cuenta de por qué y cómo la teoría resuelve el problema de la no cooperación, Schelling se empeñará en mostrar otros mecanismos internos que llevan a formas específicas de cooperación condicional. Si bien en ocasiones solo se necesita que coopere una porción específica de gente para resolver los fallos de coordinación, en otras, el problema únicamente podrá resolverse si todos, o casi todos, participan en el juego. Es más, en situaciones de exigencia real de trabajo conjunto, como en casos de emergencias sociales o de catástrofes climáticas, por ejemplo, podemos llegar a sentirnos imbuidos — desde la ética social — por un gran sentido de solidaridad y dejarnos guiar por una inviolable regla de oro. Ahora bien, si observamos la más mínima muestra de defección por parte del otro, si podemos intuir o constatar la más pequeña demostración de no correspondencia entre los propios esfuerzos de autorrestricción y los que esperamos que el resto haga, se corre el riesgo de desestimar la participación propia y violar, sin más, la regla de consenso para todos establecida. En esa dirección, como los que optan por quedarse fuera del acuerdo (la opción preferida, en lenguaje schellingniano) ${ }^{18}$ producen irritación en los que se mantienen dentro (optando por lo que no prefieren), puede llevar a estos últimos, y en ciertos casos, a levantarse en contra del agravio, rompiendo el estado de tolerancia limitada en el que se encuentran y resquebrajando el equilibrio de convivencia social subyacente ${ }^{19}$. Ejemplos de contrato hay muchos: la típica figura de la moderna estructura impositiva en las sociedades moderno-industriales o contemporáneas, los planes reguladores de reglamentación urbanística, las reglamentaciones sobre usos de la vialidad urbana o suburbana, la contribución obligatoria a la reclusión militar, las restricciones de velocidad automotriz, etc. ${ }^{20}$.

Lo interesante para nuestros fines es que, cuando se erige una norma como esta, no todos los agentes involucrados sacan igual tajada del pastel. Efectivamente, mientras algunos pueden llegar a ser beneficiados directos (o indirectos) de tal o cual acuerdo, otros deberán considerarse perjudicados directos (o indirectos) de tal medida. Respecto a ello, el ejemplo del césped de Schelling es sumamente ilustrativo, pues, además de mostrar la racionalidad de costes y beneficios de las partes involucradas, además de demostrar analíticamente la necesidad de regulación, muestra la relación asociada entre contrato y ética social. Es decir, si no disponemos de los sistemas de observación o de regu-

18. Orden de preferencias utilitarista de mayor a menor: opción preferida, la no cooperación unilateral; seguidamente, la cooperación universal; luego, la no cooperación universal, y, por último, la cooperación unilateral.

19. Para una definición de equilibrio, ver Schelling, 1989: 22-25.

20. A nivel de estructuras macro, el mejor ejemplo son las constituciones nacionales. La UE, como gobierno multinivel, también puede representar un caso típico ejemplar. 
lación directos provistos por los entornos familiares primarios, por ejemplo, si estamos obligados a pertenecer a entornos sociales constituidos por otros anónimos y si nos enfrentamos cotidianamente a restricciones de recursos, la reglamentación de los usos resulta de patente necesidad. En efecto, si todos usamos lo que queremos ocupar de un recurso $R$ en un período de escasez sin restringirnos (y todos sabemos que el resto también lo hará), lo más seguro es que el agotamiento de ese recurso $R$ termine por minar los intereses de todos. En tal sentido, si acepto restringir mis deseos de obtención de beneficios en pos del beneficio general, solicitaré que todo el mundo haga lo mismo apelando a la ética de respeto a los acuerdos o a la dureza de las sanciones disuasorias. El problema es que, como los sistemas democráticos liberales no cuentan con sistemas de monitoreo y de vigilancia completamente efectivos, la observancia a los acuerdos, en teoría suscritos por todos y definidos para todos, queda relegada al terreno de la moral pública (motivación altruista condicional o incondicional, por ejemplo) o a los mecanismos de confianza anónima horizontales establecidos entre particulares.

En definitiva, el contrato, en cualquiera de sus formas, cobra fundamento y se yergue como la solución institucional para revertir los efectos perversos de la racionalidad individual sobre los intentos de construcción colectiva de resultados sociales eficientes. En otras palabras: para restringir la presión de los deseos de maximización individual sobre la necesaria producción de sociedad. Conclusión, el contrato (en versión de compromiso de clases, economía keynesiana, capitalismo organizado) sirvió durante décadas para establecer escenarios institucionales en donde el producto social fuese mejor repartido (la relación entre capital y trabajo), restringiendo la circulación de capitales y poniendo cercas a la libertad de emprendimiento individual a costa del beneficio del factor trabajo industrial organizado ${ }^{21}$. El neoliberalismo, como ya se mencionó, es el intento por zafar dichas constricciones a la libre circulación y acumulación de capital. En lo que sigue, entregamos algunas reflexiones complementarias que emanan de la utilización del contrato como figura de resolución de la acción colectiva.

\subsection{El forced rider y la tiranía de la mayoría como implicancias}

Lo interesante de la puesta en operación del contrato es que este, teóricamente, reduce los beneficios de algunos de los que están directa o indirectamente involucrados. De esta manera, algunos agentes, sumidos en la esfera de constricción del contrato, verán reducidos sus beneficios directos, necesitando de incentivos que los compelan a vincularse a instancias sociales correctoras de los fallos de coordinación implícitos en los sistemas de intercambio.

Es una figura relativamente poco trabajada en la literatura de la acción colectiva y que denomina a la condición de productor o consumidor obligado

21. Para el análisis de la relación entre capitalismo y socialdemocracia, ver Przeworski, 1987 y 1989. Para el análisis de la idea del pacto político y de la democracia como forma de procesar conflictos, ver Przeworski, 1994, 1995 y 2010. 
de un BP. Es decir, la condición de un agente determinado que se ve involucrado de manera indirecta en el proceso de provisión de un BP y que es forzado por las agencias estatales (por ejemplo) a cooperar pasivamente en su suministro en función del logro del bienestar general (Frohlich et al., 1991; García Sobrecases, 2000; McCarthy, 2004; Cowen, s/a). En los términos expuestos, un sujeto que se ve compelido por los acuerdos de coordinación que intentan institucionalmente revertir resultados sociales subóptimos provocados por las presiones de la maximización racional individual sobre el conjunto de oportunidades del total de la población. Ahora bien, si el contrato es una estrategia correctora de la tensión entre racionalidad individual e irracionalidad colectiva, bajo los condicionantes que este impone, no todo el mundo saca igual provecho ni obtiene el mismo retorno en utilidad. Respecto de ello, bajo contrato, algunos agentes obtienen más beneficios que otros. En efecto, bajo el objeto de proveer bienes de uso colectivo, la implementación de restricciones externas a la comunidad (estatales) o internas a ella (provenientes de liderazgos internos a la comunidad) provoca, por un lado, el problema de la asimetría en la estructura de costes y beneficios entre agentes y, por otro, el consumo forzado.

Debido a los efectos de la imposición del contrato (obligatoriedad de consumo y pago), vemos como entonces, en la provisión de BP, se hace comprensible la emergencia de una figura que, aún no viendo beneficio directo en la provisión de un bien determinado, ha de aceptar cooperar forzosa e indirectamente en la procura del interés de todos, situación que nos lleva a relevar otro problema tangencialmente asociado: el de la tiranía de la mayoría (Gargarella, 1999), situación que pone en evidencia otro asunto complementario: el de la amplitud mayor de intereses.

Pues bien, a efectos de ilustrar la utilidad del mecanismo descrito, pasamos a caracterizar el rediseño institucional chileno. Pero, antes de ello, quisiéramos señalar, como nota preliminar, que, a fines de los años sesenta y debido al auge de las luchas sociales democráticas propias del tercer cuarto del siglo $\mathrm{xx}$, el beneficiario directo (o el sector más beneficiado) del contrato o del compromiso de clases establecido era el sector laboral, mientras que el perjudicado directo (o menos beneficiado) era el capital ${ }^{22}$. Eso, por cierto, a nivel mundial, puesto que el protoestado benefactor latinoamericano solo era su espejo mal conformado. De hecho, algunas cifras recabadas por el autor y recogidas en entrevistas exploratorias hechas a investigadores del CENDA en Santiago de Chile, por ejemplo, señalan que la estructura de la distribución funcional de la renta ${ }^{23}$ para el país en 1973, es decir, la estructura de los beneficios para el capital y para el trabajo, era de un 60\% aproximadamente para el trabajo y de un 40\% aproximadamente para el capital. En 1990, la proporción se había

22. El pacto de postguerra entre capital y trabajo consistía en que el trabajo renunciaba a «la democracia económica e industrial, a cambio del reconocimiento oficial del papel de los sindicatos obreros en la negociación colectiva: ustedes se olvidan de la democracia en el puesto de trabajo y, a cambio, les reconocemos derechos civiles básicos en ese puesto de trabajo» (Domènech, 2013: 115).

23. Un indicador olvidado por la teoría económica neoclásica. 
invertido, lo que, en otras palabras, quiere decir que, en definitiva, lo que la dictadura hizo con su rediseño fue modificar sustancialmente la estructura de la distribución funcional de la renta en Chile. Hoy, veinticinco años después, esta se mantiene igual que a comienzos de la transición.

\section{El metadiseño institucional implantado: las bases de la institucionalidad}

¿Cuál es el modelo de sociedad que impusieron luego del quiebre unilateral del contrato y que vino a reeemplazar el modelo centrado en el trabajo? ¿Cuál es el modelo que posibilita la restitución del poder de clase, aunque ahora se encuentre en manos del capital financiero y ya no del industrial? En lo que sigue, se describirá, grosso modo, tanto las caracteristicas propias del diseño institucional neoliberal implantado en Chile entre fines de la década de 1970 y fines de la de 1980, como su correlato en el plano de la acción social: la inacción colectiva y el emprendimiento individual.

\subsection{El metadiseño institucional implantado}

Para nosotros, el neoliberalismo es una teoría de lo social, lo político y lo económico (e incluso lo cultural) que señala que la mejor manera de promover el bienestar dentro de la población consiste en no restringir el supuestamente espontáneo y libre desarrollo de las capacidades y de las libertades emprendedoras del individuo. Todo ello dentro de un diseño institucional marcado por el respeto a los derechos de la propiedad privada, por la libertad de emprendimiento individual y, por tanto, a favor de robustos mercados libres de regulación estatal. Dentro de ello, el Estado solo debe crear, fortalecer y preservar dichos imperativos, además de abstenerse de intervenir en el libre desarrollo de dichas capacidades individuales. Junto a ello, debe garantizar y asegurar, incluso mediante la fuerza, el correcto funcionamiento de los mercados privados y la estructura de propiedad privada resultante. Las libertades individuales, y ya no los derechos colectivos de las mayorías, se garantizan por medio de la promoción y del respeto de la libertad de mercado y de comercio (Gárate, 2014; Harvey, 2007; Viera, 2013). Las motivaciones, en cuanto a psicología política ${ }^{24}$, previstas en la teoría económica estándar, son la maximización individual egoísta, la cual — según la famosa aseveración de Smith—generará más beneficio colectivo (BP) que si una institución central supraindividual le dedicara tiempo y empeño organizado (Elster, 2010). Los sistemas privados de intercambio han existido siempre, no obstante, la institución del mercado moderno es una creación política (cfr. Polanyi, 2003) que el liberalismo

24. Para fines estrictamente operativos, entenderemos genéricamente acá la psicología política como la disposición individual a contribuir $-\mathrm{O}$ no- a la producción de un BP. En ese sentido, creemos - con Pettit- que las modificaciones en el metadiseño institucional necesariamente han afectado a dicha disposición en formato individual. Lo macro ha afectado a lo micro y ello ha generado esta nueva subjetividad liberal tan propia de lo que, en ciertos círculos académicos del país, se ha dado en llamar «sociedad neoliberal avanzada». 
académico, político y económico ha impuesto y ha legitimado de manera incondicional en el sentido común contemporáneo global. En ese aspecto, en las áreas o esferas en donde los mercados privados no existen (o donde no existían hasta los años ochenta, como en las esferas de la educación, la salud, la seguridad social, el agua, etc.), deben ser creados artificialmente por el Estado para asegurar un beneficio privado al capital (comodificación). No obstante, una vez creados por el Estado, este, de acuerdo con dicho paradigma, debe replegarse, pues no puede obtener toda la información necesaria para coordinar una economía eficiente y porque dicha institución central será fácilmente capturable por poderosos grupos corporativos de interés que distorsionarán los marcos de una economía eficiente y próspera. Por tanto, la fe liberal se basará, digamos, en dos dogmas: la autorregulación y el equilibrio y la benevolencia del mercado (De Francisco, 2007), dogmas basados en el citado mecanismo de mano invisible previsto por Smith. O, más bien, por la lectura liberal de Smith.

Pero, ¿cómo se llegó a este tipo de escenario ideológico hegemónico? Tras el triunfo del liberalismo norteamericano en 1945, el capital de ese país había impuesto un nuevo orden mundial erigido por medio de un conjunto de instituciones conocidas como «los acuerdos de Bretton Woods». Se crearon instituciones financieras internacionales (ONU, FMI, BM, Banco de Pagos Internacionales de Basel) cuyo objetivo no era otro que el de promocionar la estabilidad en las relaciones internacionales en el contexto de un capitalismo de tipo reformado o embridado (de base keynesiana), incentivando, además, el libre comercio de bienes industriales mediante un sistema de intercambio de tipos de cambio fijo sujeto siempre a la convertibilidad del dólar norteamericano en oro (el famoso patrón oro). En ese contexto, y ya a fines de la década de 1960, las políticas que fomentaban las industrias nacionales mediante subvenciones o protección arancelaria (el modelo de industrialización sustitutiva de importaciones, o ISI), y que habían dominado las estrategias latinoamericanas de desarrollo económico y social, estaban cayendo en el descrédito público (político y académico). Con la economía mundial completa en recesión, se requería un nuevo enfoque que remeciera las regulaciones al capital y diera rienda suelta a las pulsiones más básicas de los mercados privados.

En efecto, el modelo de control a los capitales funcionó, y funcionó relativamente bien por un tiempo. De hecho, el capitalismo nunca había sido tan estable como entre el fin de la Segunda Guerra Mundial y los comienzos de la reaganomics (1945 y 1980). Pero la crisis del petróleo, el auge de los movimientos sociales populares demandantes de mayores derechos socioeconómicos y distributivos, de la accción colectiva sindical y del mundo del trabajo, de los movimientos populares urbanos, anticoloniales y antiimperiales agudizaron la crisis económica a un nivel tal que la transformaron en una crisis política generalizada, lo cual provocó que el modelo de control y regulación de capital colapsara a nivel mundial en la segunda mitad de los años setenta. A fines de la década de 1960, el capital había llegado a temer por la supervivencia del modelo de acumulación a escala mundial, y había que reaccionar. ¡Y vaya que reaccionaron! El golpe de Estado en Chile fue el comienzo de la 
contrarrevolución desdemocratizadora y el retorno al capitalismo liberal desregulado y financiero de antes de la Gran Guerra. Debían cambiar la situación. Sumado a ello, y de manera paralela, las potencias vencidas en la Segunda Guerra Mundial, Alemania y Japón, ya se perfilaban como grandes potencias exportadoras, lo que traía aparejada la reducción de las tasas de ganancia del capital norteamericano. A finales de la década de 1960, el liberalismo embridado, reformado u organizado estatalmente, que se edificaba sobre un «compromiso de clase» entre capital y trabajo (garante fundamental tanto de la paz social como de la productividad), comienza a desmoronarse, tanto a escala internacional como nacional. Como señaláramos en la nota 22, y citando a Domènech, dicho pacto consistía, fundamentalmente y en términos genéricos (sobre todo en el modelo socialdemócrata europeo, que, en cierto sentido, inspira el modelo nacional y popular desarrollista latinoamericano), en que el mundo laboral renunciaba a

[...] la democracia económica e industrial, a cambio del reconocimiento oficial del papel de los sindicatos obreros en la negociación colectiva: ustedes se olvidan de la democracia en el puesto de trabajo y, a cambio, les reconocemos derechos civiles básicos en ese puesto de trabajo — expresión, reunión, asociación-y capacidad jurídica para negociar aumentos del salario real en función de aumentos de productividad. (Domènech, 2013a: 115)

Un pacto político - un contrato- basado en cooperación condicional, donde ambos agentes ponían de su parte para mantener un nivel eficiente de producción y distribución. Es decir, donde ambos colaboraban para obtener y disfrutar de bienes producidos cooperativamente (cooperación mutua condicional, escenario que recuerda lo que, en teoría de juegos, se denomina «el juego del seguro»: yo coopero solo si el otro coopera).

Pues bien, las políticas keynesianas de postguerra centradas en la promoción de la demanda agregada y el control de capital a nivel internacional habían dejado de funcionar, con lo que los tipos de cambio fijos ya eran incompatibles con la libertad de los flujos de capital que hasta el momento habían sido controlados. Se estaba frente a una grave crisis de acumulación de capital. En aquel escenario político, económico y académico, la izquierda había congregado un considerable poder detrás de estos programas de desarrollo, el programa nacional y popular. No obstante, y pese a que las estrategias que esta alentaba ya se habían demostrado completamente incompatibles con las exigencias de acumulación de capital, no fueron mucho más allá de las tradicionales soluciones, o bien socialdemócratas o bien corporativistas, situación que desencadenó una polarización del debate y la acción política entre socialdemócratas — partidarios de la planificación central - y los intereses de quienes alentaban el restablecimiento de las libertades de mercado, el poder financiero y las corporaciones transnacionales (Harvey, 2007). Se pasó de una situación de cooperación condicional, donde ambos ganaban algo (contrato social), a una en que un actor — debido a la crisis de acumulación de capital y argumentando que se estaba 
afectando a la estructura de propiedad (reforma agraria, expropiaciones, nacionalizaciones)—, decide, reactiva y unilateralmente, pasar a la no cooperación incondicional, con lo que rompe el acuerdo y determina imponer nuevas reglas del juego. Argumentan que la organización política de los trabajadores, con su actuar, ha sobrepasado los límites admisibles por la estructura de propiedad propia de una economía capitalista periférica ${ }^{25}$. En ese sentido, y desde la perspectiva del capital, la no cooperación se torna una estrategia necesaria, reactiva y unilateral frente a la evidencia de que el otro jugador ha roto el compromiso inicial (las amenazas comenzaron a ser creíbles). Había que reaccionar para no seguir empeorando la propia condición. Se prefirió pasar del forced rider (cooperación condicional, contención de beneficios a corto plazo, aplazamiento de la gratificación) a la no cooperación unilateral e incondicional. Pero luego, bajo la influencia de los teóricos de Chicago, y porque comprendieron que ya no tenían contendores de peso, podían reestructurar el esquema institucional completo a medida, y lo rediseñaron. Así, los beneficios futuros esperados y derivados del rompimiento unilateral del pacto (freno a la promoción del «área social» y expectativas de apropiación de los resultados de la nueva economía) eran mayores que los costes estimados por romperlo (deslegitimación política propia de un acto ilegal que les aseguraba el cambio de reglas del juego). En un primer momento, prefirieron pagar el coste de ser acusados de no demócratas antes de perderlo todo. En momentos posteriores, desarrollaron las ideas que les asegurarían el control de la economía excluyente que el neoliberalismo resultó creando ("hay que cuidar a los ricos» en el corto plazo, para que estos inviertan y gesten y gestionen la nueva economía ${ }^{26}$. Así, cooperar dejaba de tener incentivos para el capital.

El objetivo de las instituciones liberalizadoras fue entonces el de la reorganización de la economía en base a los supuestos teóricos del monetarismo económico propagado desde las aulas de la Universidad de Chicago y que promovían el pensamiento de la Escuela Austríaca (Hayek) ${ }^{27}$. Revirtieron todos los procesos de nacionalización y estatización, y privatizaron ${ }^{28}$ todos los activos públicos que pudieron: los recursos básicos de asistencia social (salud, educa-

25. Creemos que las preferencias siempre fueron de primer orden, pero restringidas por un contrato de compromiso. Por definición, el capital tiene preferencias utilitaristas de primer orden. Hay que obligarlo a montar un esquema de cooperación condicional. El pacto entre capital y trabajo desarrollista representó medianamente ese esquema de inclusión propio de la sociedad laboral.

26. «Cuando el capital obtiene ciertos privilegios, en poco tiempo los presenta como derechos adquiridos y los naturaliza utilizando los aparatos que controla y produce la superestructura [...] como si fuera parte constitutiva del acervo cultural de la sociedad» (Gálvez y Kremerman, 2016).

27. Dicha perspectiva se venía enseñando marginalmente desde décadas atrás, pero no gozaba del prestigio necesario para erigirse como modelo teórico hegemónico dentro de la ciencia económica al uso. El modelo hegemónico del industrialismo y de la sociedad del trabajo era, sin duda, el keynesianismo, la promoción del gasto público y de la demanda agregada.

28. Traspasaron BP o comunales a la explotación privada y desregulada. Mientras la derecha política vendía, la derecha económica compraba a precios irrisorios. 
ción y pensiones); los recursos naturales (industria pesquera, maderera, minera), y abrieron las economías (nacionalismo económico) a la libre circulación de capitales globales y a la inversión extranjera directa, con lo que favorecieron una mayor libertad de comercio. El mercado de trabajo fue «liberado» de las restricciones político-institucionales (sindicatos) propias de modelos más desarrollistas, y el poder político de clase acumulado en décadas de luchas sociales de carácter distributivo fue completamente destruido: la acción colectiva de clase $^{29}$. Esto implicó enfrentarse y destruir el poder sindical, atacar todas las formas de cooperación y solidaridad social que frenaban la libre competencia, desmantelar los compromisos sociales del Estado, privatizar empresas públicas, reducir impuestos al capital ${ }^{30}$, incentivar la libre iniciativa individual y crear un clima favorable para los negocios privados, eliminando toda reglamentación represiva a las fuerzas espontáneas de sus mercados. Todas las formas de solidaridad existentes en lo social — «la sociedad»— iban a ser disueltas en favor de esquemas basados en el individualismo, en la propiedad privada, en la responsabilidad personal y en los valores familiares ${ }^{31}$. Transformaron, así, comunidades nacionales productoras y vendedoras con soberanía económica y política relativa en economías periféricas compradoras. En ese sentido, neoliberalización es sinónimo de financiarización general y global de la esfera económica. Es la subordinación de la economía real a la especulación bancaria ${ }^{32}$. También de complejos, oscuros y a veces antidemocráticos procesos de acumulación de poder político y económico sin precedentes en la historia, lo que significa la intensificación del dominio del capital financiero por encima de las restantes dimensiones de la esfera económica (así como por encima de la vida cotidiana), así como el sentido y la orientación de los mecanismos estatales que canalizan los sistemas privados de intercambio.

Consecuencia de todo ello, y en el terreno de lo estrictamente económico, fue el comienzo del sostenido proceso de descenso de los salarios reales y del desemparejamiento de los salarios reales respecto de la tasa de productividad (cfr. Fundación Sol, 2013). En efecto, a estas alturas del texto, ya podemos identificar y relevar la principal innovación del llamado neoliberalismo y que se encuentra en la base de lo que hoy conocemos como la sociedad del consumo: el desacoplamiento entre demanda efectiva agregada y salarios reales, y la sub-

29. El neoliberalismo, como teoría de las prácticas económico-políticas, ha perdido todas las batallas académicas de valor, sin embargo, sigue implementándose hasta el día de hoy en economías dependientes y periféricas. ¿Una cuestión de poder?

30. Los impuestos sobre las empresas se redujeron abruptamente y el tipo máximo sobre las personas en EE. UU. se redujo del $70 \%$ al $28 \%$.

31. "QQuién es la sociedad? No existe tal cosa. Lo que existe son hombres y mujeres individuales, existen las familias», señalaba Thatcher a comienzos de los años ochenta. «La economía es el método» y «el objetivo es cambiar el corazón y el alma», también llegó a afirmar. Cabe recordar también el discurso TINA («There is not alternative») como eslogan opositor a los esquemas económico-políticos centrados en el Estado.

32. Lo que involucra, sin lugar a dudas, complejos procesos legales, políticos, institucionales, militares y de desplazamiento del poder desde el mundo de la producción hacia el mundo de los bancos y las finanzas. El casino especulativo y no productivo. 
secuente financiación de la demanda efectiva y el consumo a partir del fraude financiero global y el crédito barato.

De esta manera fue como, rompiendo las reglas del juego establecidas entre capital y trabajo ${ }^{33}$, se llegó a la principal característica del escenario económicopolítico actual: la restitución del poder económico a las clases altas y una de sus consecuencias perversas, la mayor desigualdad social vista en los últimos siglos. En efecto, la crisis que detonó en la década de 1980 afectó a una modalidad específica de organización de la esfera económica y de relación entre el Estado, el mercado y la democracia, es decir, al sistema de poder articulado y empotrado a ella. De esta manera, se instalan una serie de políticas económicas destinadas a desmontar los mecanismos institucionales intervencionistas de base keynesiana y a ampliar los márgenes de libertad de los mercados privados: el capital financiero y bancario (sectores de las economías centrales ligados al comercio exterior y al sector financiero global) y círculos doctrinarios de carácter académico vinculados a dichos actores. Nos referimos al llamado Consenso de Washington, el cual «consistía en diez ingredientes de política económica: 1) disciplina fiscal; 2) priorización del gasto público en áreas de alto retorno económico; 3) reforma tributaria; 4) tasas positivas de interés fijadas por el mercado; 5) tipos de cambio competitivos y liberalización financiera; 6) políticas comerciales liberales; 7) apertura a la inversión extranjera; 8) privatizaciones; 9) desregulación amplia; 10) protección a la propiedad privada» (Williamson, 1990 y 1993, en Vilas, 2000: 2).

Como sabemos, el Estado (quien opera el por nosotros denominado y ya expuesto contrato), en términos teóricos genéricos, es la institucionalización de las relaciones de poder dispuestas en la sociedad y articula los intereses corporativos hegemónicos nacionales con el sistema político y económico internacional. Pero, en términos organizacionales, el papel del Estado debía reducirse a un nivel mínimo de expresión, y reservarse solo para cumplir con funciones de provisión de BP en áreas donde los sectores privados no tuvieran incentivos para intervenir (cfr. Nozick, 1988). Sería el Estado subsidiario. Ello no obstante, el desmantelamiento de los mecanismos de intervención y de las regulaciones universalistas proestatales de carácter keynesiano requerían de una concentración importante de facultades gubernamentales. Esto es, para poder impulsar tanto las aperturas necesarias para asegurar el libre flujo de capitales como las desregulaciones necesarias para el libre comercio, había que generar hegemonías que lograran vencer las resistencias sociales y políticas que se oponían al desmantelamiento y el cambio de rumbo. Había que modificar los equilibrios existentes y romper la estructura de correlación de fuerzas. Había que romper la acción colectiva de clase. En algunos países, las modificaciones fueron hechas bajo dictaduras militares, como fue el caso chileno; en otros, bajo programas neoconservadores de carácter autoritario, como los anglonorteamericanos.

33. Reglas que, en cierto sentido, expresaban los logros que el trabajo organizado y los movimientos sociales democratizadores venían consiguiendo desde fines del siglo XIX. 
En el nivel constitucional, todo esto implicó en el país la creación de un Estado supuestamente neutral, eficiente ${ }^{34}$, autoritario y que pudiera lograr la refundación institucional necesaria. (Recordemos que, para Jaime Guzmán, la democracia era un obstáculo para el ejercicio del derecho de propiedad y la libre empresa.) En lo social, se creó una esfera pública no gubernamental (la sociedad civil, los «cuerpos intermedios») que reemplazara la politizada e ideologizada vida pública chilena de comienzos de los años setenta, preñada de orientación colectiva de clase. A nivel micro, se promovió la creación de una identidad económica y política, una subjetividad imbuida de individualismo (inacción colectiva) y de pautas postmodernas de consumo inmediatista y crédito. Cuando se modifica la estructura del diseño institucional, cuando cambia la distribución y el uso de los recursos sociales, cambian — como resultadolas relaciones entre los individuos y los grupos sociales, así como sus posicionamientos específicos en las estructuras de jerarquía y poder. Pero, sumado a ello, también cambian las capacidades de acción y de autoimposición de objetivos y metas a alcanzar: la estructura de incentivos y las creencias (subjetivas) sobre las oportunidades (objetivas). No está de más decir que dicha reestructuración genera ganadores y perdedores. El mayor peso asignado al mercado privado neoliberal ${ }^{35}$ implicó mayor poder político y económico de los agentes que consiguieron posiciones políticas importantes dentro de él. A diferencia de aquellas posiciones, los trabajadores y los gobiernos sensibles a las demandas del sector laboral fueron responsabilizados de la crisis del capitalismo del Estado céntrico y fueron subordinados o simplemente destruidos (dirigentes ilegalizados, perseguidos, exiliados, desorganizados, asesinados). Como sabemos, y en términos estrictamente nacionales, en Chile, los aspectos básicos de esta nueva institucionalidad, el proyecto ideológico refundacional que se impulsó en los diecisiete años de dictadura aún permanece inalterado. Nos referimos al sistema tributario (1974-1984), al sistema bancario (1975-1986), al Plan Laboral y a la subcontratación (1979), a la Constitución de 1980, a la privatización de la seguridad social a través de la creación de las asociaciones de fondos de pensiones - AFP - (1981), a la privatización y al abandono de la educación pública (1981), a la implantación del sistema de salud -ISAPRES — (1981), a la desnacionalización del cobre (1981), a la privatización del agua (1981) y al fomento forestal (1984). Hasta comienzos de marzo de aquel año 1990, el régimen se esmeró en aprobar leyes orgánicas para atar los contenidos de la transición. En efecto, si el diseño se empezó a implementar desde fines de la década de 1970 (plebiscito de 1978 y de 1980), un conjunto no menor

34. Como señala Vilas: «El ajuste económico resumido en el “Consenso de Washington” y, más en general, el exitoso funcionamiento de la economía, demandan reformas profundas en el diseño y funcionamiento del aparato estatal, y no sólo la reducción de éste a su expresión mínima. La cuestión es la eficacia del Estado una vez que éste ha alcanzado su tamaño óptimo» (Vilas, 2000: 7).

35. A diferencia del pensamiento económico hegemónico desde los años treinta, se comienza a dar al mercado reconocimiento doctrinario y político público como mecanismo más eficiente en la asignación de recursos que el Estado. 
de reformas se terminaron de definir e implantar pocos días antes del inicio formal de la transición, esto es, el cambio de mando de marzo de 1990 (plebiscito de julio de 1989, por ejemplo). Así, a las redefiniciones estructurales en materia constitucional, laboral, de educación, de pensiones, de salud, de aguas, de partidos políticos, de gobierno y de Administración regional, etc., durante los últimos meses de la dictadura militar, se agregaron cambios en materia de banco central, aborto, estado de excepción, fuerzas armadas y de orden, entre otras. Pues bien, las consecuencias de la implantación de dicho esquema en la población están a la vista: fragmentación de los mercados de trabajo, tercerización, subempleo y precarización, salarios reales estancados o deteriorados comparables con los niveles logrados en los años setenta, aumento de la desigualdad, caída de la calidad de la cobertura de los servicios públicos básicos, degradación ambiental, inseguridad ciudadana, etc.

\subsection{La psicología política promovida: la acción individual por encima de la de carácter colectivo}

Ahora bien, como señala Garretón (2002), en términos sociopolíticos, el paradigma político y académico hegemónico en la región (y también a nivel mundial) diagnosticó y prescribió durante décadas, por un lado, la correspondencia fuerte entre estructura y actor, $y$, por otro, tanto el predominio de esta sobre el actor como «la existencia de un eje central constitutivo de la acción colectiva y los actores sociales». Con la crisis de la sociedad del trabajo y el modelo fordista, este esquema sociopolítico básico ya no daría cuenta de la realidad del momento y estaría absolutamente agotado y obsoleto. Es decir, la matriz sociopolítica que operó y que constituyó la estructura de las economías centrales y las sociedades de la región entre fines de la Segunda Guerra Mundial y la crisis de mediados de la década de 1970, esto es, la relación particular entre Estado, régimen y partidos políticos y sociedad civil fue modificada sustancialmente, autoritariamente. En efecto, la matriz sociopolítica clásica promovía la fusión de diferentes procesos (desarrollo, modernización, integración social y autonomía nacional), articulando de manera ajustada al Estado desarrollista, a los partidos políticos y a los actores sociales. Dentro de esta matriz, el Estado desempeñaba un rol central para la acción colectiva, la organizaba centralmente entretejiéndose con lo social y la movilización de intereses corporativos. El movimiento nacional popular representaba y movilizaba la creación populista central de este Estado promotor: el pueblo, quien le daba soporte y legitimidad. Dicho modelo ilustra, pues, claramente el modelo prototípico de resolución centralizada del problema de la acción colectiva antes descrito. La destrucción de la matriz nacional popular hecha a partir de mediados de los años setenta describe un proceso de transformaciones institucionales estructurales. (El agotamiento del modelo de industrialización sustitutiva de importaciones - modelo ISI — fue reemplazado por esquemas que priorizan el rol del sector privado y la libre circulación de capital dentro de la economía globalizada.) El diseño institucional cambió por completo, lo que trajo consigo modificaciones 
y consecuencias profundas para los actores sociales, la relación entre estos y el Estado y las formas de acción colectiva. Se pasará de la acción colectiva reivindicativa y demandante de Estado y de derechos (socioeconómicos) colectivos a la inacción colectiva y al paradigma de las libertades individuales. Tanto la desarticulación de los actores sociales y políticos clásicos, como la explosión de las identidades de carácter adscriptivo o comunitario, como las nuevas formas de exclusión, segregación, expulsión y la conformación de actores económicos a nivel sobrenacional (global), hicieron pedazos los principios de referencia básicos de la polis o del Estado nacional. Esta tenía dos ejes fundamentales: el trabajo y la política. Los llamados movimientos sociales articulaban ambos ejes. Hoy, la sociedad postindustrial, postfordista, neoliberal o neocapitalista, la sociedad del riesgo, el capitalismo contrarreformado, entre otras denominaciones, tienen como ejes constitutivos centrales al individuo, al consumo y a la información.

Si entendemos el quiebre unilateral del contrato como un problema de no cooperación entre clases o entre sectores sociales determinados, entre capital y trabajo, el resultado es un modelo de sociedad - o de economía- donde no hay espacios para la negociación entre actores sociales (capital y trabajo) y donde hay una concentración completa de poder político y económico; poder que será utilizado para el establecimiento de las reglas del juego y la fijación del sentido y la dirección de la producción de la sociedad. Rompieron el contrato desarticulando de manera violenta la acción colectiva popular de clase (destrucción de la organización social y obrera), privatizando el patrimonio colectivo (propiedad pública) e imponiendo una hegemonía cultural neoconservadora a nivel de psicología política, para así poder darle sustentabilidad en el tiempo (legitimación simbólica). Y todo ello para volver a dirigir el proceso de producción y acumulación en su propio beneficio.

De esta manera, el neoliberalismo consiste fundamentalmente en desembridar al capital de los constreñimientos institucionales. Consiste en desinstitucionalizar la acción colectiva organizada socialmente (Castel et al., 2013), consiste en destruir los soportes que vinculan legal y constitucionalmente a los agentes privados a un contrato que restringe la acumulación de capital. La acción colectiva en formato político (el modelo nacional y popular desarrollista) ponía trabas a la necesaria vuelta a la reproducción ampliada del capital. Por ello, había que desvincular necesariamente - y desde el Estado- lo social de lo político. Parafraseando libremente los conceptos de Keynes, si el capitalismo embridado —o reformado — había significado la eutanasia del rentista, el neoliberalismo - el capitalismo contrarreformado - no ha sido otra cosa que la venganza de este (Domènech, 2006). En resumidas cuentas, y en palabras de Harvey (2007): el neoliberalismo, desde su comienzo, fue un proyecto para lograr la restauración del poder de clase.

Así, el llamado neoliberalismo modificará, desde el Estado, la acción colectiva entendida durante casi todo el siglo xx capitalista, como cooperación horizontal de clase orientada al proceso, reemplazándola por la competencia individual orientada al resultado. Nos hizo renunciar autoritariamente al para- 
digma de los derechos colectivos y nos hizo consentir bajo coacción —una especializada coacción que se hizo ver como un proceso ilusoriamente consensuado- y aceptar la implantación del paradigma de las libertades individuales. Sacó a los pobres del estado político de cooperación horizontal de clase (conciencia para sí) y los puso a competir entre ellos.

\section{Reflexiones finales}

El texto recién expuesto se sostiene sobre la base de la idea de que todo el rediseño institucional neoliberal aplicado en Chile, proceso que se fundamentó en la descolectivización completa de la política, la economía y la sociedad, provino del rompimiento unilateral del contrato social entre clases keynesiano ocurrido en la década de 1970 y que afectó, con su influencia, prácticamente a toda la economía mundial. Las categorías con las que se trabajó la idea de la descolectivización institucional, es decir, la ruptura unilateral del compromiso interclases, fueron el contrato social, la crisis del universalismo y de la dinámica de la descolectivización, el quiebre forzado del contrato y la aplicación incondicional del modelo económico liberal. Dentro de ello, resultan centrales los conceptos de: (1) contrato social entendido como recurso teórico-político de coordinación que restringe las pulsiones maximizadoras de primer orden de los agentes presentes en una situación de intercambio determinada (juego), y (2) acumulación por desposesión, entendido como el amplio, complejo y profundo conjunto de procesos de privatización, desmantelamiento de derechos universales, desnacionalización, precarización y trasferencia de riqueza bottom up (de abajo hacia arriba) vividos por la población de clases media y baja entre mediados de la década de 1970 y que continúan hasta la fecha. El primero tiene un carácter central desde el punto de vista analítico. El segundo lo tiene desde el punto de vista del relato de la economía política subyacente. Como vimos, el diseño institucional afecta directa (o indirectamente) a la economía de una comunidad de intereses, pero también a las creencias sociales, políticas y económicas de las personas que la componen. Por otro, el análisis del rediseño, tanto de la economía como de la reorientación del diseño constitucional (arquitectura de las reglas del juego) y de lo cultural-institucional (arquitectura de la psicología política), puede servir para la realización del análisis de los beneficiados directos e indirectos generados y de los perjudicados directos e indirectos: la economía política de la descolectivización.

Si entendemos el rompimiento unilateral del contrato social entre clases como un problema de acción colectiva entre sectores sociales determinados (clases sociales, segmentos de clase), lo que involucra un problema de no cooperación de agentes corporados de clase (entre capital y trabajo), desde una perspectiva amplia, los diversos procesos de descolectivización constitucional, organizacional e institucional han incidido profundamente en la manera como nos relacionamos como agentes con el Estado y con los demás en la esfera pública (y qué resultados obtenemos para cada cual), en la manera como nos relacionamos como agentes dentro de la esfera económica (y qué resultados 
obtenemos para cada cual) y en la manera como nos relacionamos como sujetos dentro de la esfera social (y qué resultados obtenemos para cada cual). Esto es, las reglas del juego constitucional e institucional nos han ido llevando a cierto tipo de creencias y de comportamientos en lo público y en lo privado, situación que actualmente puede dar cuenta claramente de las diferencias en la estructura de logros políticos y económicos lograda (¿prevista?) para unos y otros. De acuerdo con ello, y en lo estrictamente económico, si bien el país, en las últimas tres décadas, ha venido mostrando tasas de crecimiento elevadas, la estructura distributiva chilena es claramente asimétrica en cuanto a la distribución de los recursos generados. Complementario a ello, y en cuanto a lo psicopolítico, el rediseño ha generado condiciones institucionales que han desvalorizado en la población la acción de tipo colectivo como recurso significativo para la consecución de resultados sociales relevantes, lo cual ha promovido la acción individual. En tal sentido, el rediseño completo de la sociedad chilena ha logrado sus objetivos esperados también por el éxito de los procesos de legitimación simbólica asociados, que, a nuestro juicio, tienen relación con la revolución cultural (neoconservadora) impuesta y que, en cierta medida, posibilitó y sustentó el nuevo modelo: la modificación de preferencias respecto al modo en que funciona lo social, lo político y lo económico (los valores promovidos desde el Estado: la iniciativa individual, el lucro desatado, el individualismo, la desconfianza en lo colectivo, la política y lo público). En ese contexto, y puntualmente respecto de la idea de lo colectivo, dicho esquema vendría asociado a la caída forzada de la actividad colectiva como forma relevante de acción social — sobre todo de sectores medios y bajos—, situación que, a su vez, habría ejercido importantes impactos en la esfera política, cultural y económica. Solo basta con ver la caída de la tasa de ganancia del trabajo medido en salarios reales de la población trabajadora a nivel mundial y nacional en los últimos cuarenta años para ilustrar el argumento. Respecto de ello, el diseño institucional (creación intencionada de mecanismos que orienten las decisiones de los individuos con el fin de promover resultados socialmente valiosos) es un tema de estado vinculado a la conformación de lo colectivo y de sus reglas de juego, por ello, principalmente un tema de lo político (la gestión democrática y deliberativa de lo colectivo), y no de la política (el negocio privado de la representación política, de la gestión de la soberanía, de la provisión de BP, de la autonomía de la política respecto de lo social). Es decir, es un tema de diseño del Estado. Pues bien, el auge económico asimétrico y regresivamente concentrador de los últimos treinta años en la historia económica del país (y que se corresponden con el auge de monetarismo en teoría económica en los últimos treinta años de la disciplina), solo se entiende considerando una caída de la idea del contrato social entre agentes (entre agentes corporados con intereses diferentes: clases sociales).

En definitiva, el modelo de sociedad implantado es el modelo de una oligarquía global con versiones nacionales que persiste en la mantención de privilegios reestablecidos después de los años setenta, que distorsiona tanto la igualdad política como la económica (tanto la democracia como el mercado) 
y que en cuarenta años ha ido concentrando poder político y económico para diseñar instituciones a medida. Un modelo que, propugnando la ausencia de regulación y la maximización de los bienes privados más que de los públicos, promueve a quienes se deshicieron de los «lastres» de la política para poder decidir unilateralmente los sentidos de la producción de la sociedad. Un modelo de sociedad que prevé ex ante la movilidad social y el progreso por la vía del crecimiento desregulado con un Estado no involucrado en la protección. Los que no van consiguiendo éxito individual se van quedado atrás y se las tienen que arreglar solos para llegar a un nivel que les permita competir con el resto. Un Estado que no protege. La centralidad del trabajo y la política fue sustituida por la centralidad de la economía y el consumo. La centralidad de las libertades individuales reemplazó a la de los derechos colectivos (Castel et al., 2013). En definitiva, un modelo que destruyó el tejido social bloqueando la cooperación horizontal de clase (en formato colectivo) y que puso a los pobres a competir entre sí (en formato individual). Así, se logró configurar de cierto modo la instauración de un régimen político (fuera de la empresa) y laboral (dentro de la empresa) que bloquea la participación política real y la negociación colectiva desanclando lo social y lo político, que impuso autoritariamente la privatización de activos públicos, las políticas sociales regresivas, etc., y que —en su conjunto y en cierta medida - promovió como efecto lateral un proceso de transferencia de riqueza bottom up nunca antes visto en la historia moderna. La decisión unilateral de quiebre deriva de la caída de la tasa de ganancia del capital y de la percepción de los sectores asociados al capital del riesgo de la caída del proceso de acumulación general si es que no se actuaba firmemente. Ello se posibilitó solo sobre la base de la caída inducida de la actividad colectiva como forma relevante de acción social de parte de las clases medias y trabajadoras, así como del vaciamiento y la despolitización de la esfera social y económica, lo cual generó - como consecuencia- la ya referida importante diferenciación en los resultados socioeconómicos obtenidos por los diferentes grupos sociales de la población. La descolectivización y la desuniversalización no tienen que ver solo con el orden de la cuestión de la política vista en abstracto, sino que tienen que ver con los resultados económicos reales obtenidos por cada parte dentro del juego social. Insistimos: la desigualdad económica es consecuencia de la desigualdad política; la desigualdad económica es consecuencia de la desigualdad en la estructura de distribución del poder político.

Por último, quisiéramos aclarar que el texto tiene algunas limitaciones y proyecciones. Sobre lo primero, quisiéramos señalar que, por ser laterales al razonamiento central - la idea de la restricción institucional, su fundamento y sus consecuencias-, el desarrollo de algunas categorías tales como psicología política y/o cultura política y económica han quedado fuera de este escrito. También el tratamiento específico y relacionado sobre el problema de la propiedad, esto es, la reflexión republicana acerca de la desaparición de la idea de la función social de la propiedad en el entramado jurídico institucional chileno (existió en la Constitución de 1925, pero ya no aparece en la de 1980). Precisamente las primeras cuestiones señaladas se constituyen como los elementos 
principales a abordar en los próximos escritos del autor: la profundización del diseño institucional. Dentro de ellas, por ejemplo, tendrán un lugar importante dos interrogantes micro: 1) cómo se produce, a nivel causal e intencional, el cambio de creencias, de preferencias y de comportamiento público orientado hacia lo privado, y 2) si los agentes tienen algunas creencias determinadas acerca de si el nuevo esquema impuesto coactivamente ha restringido su conjunto de oportunidades. Sin lugar a dudas, dos cuestiones fundamentales para comprender el aspecto «cultural» de la legitimación y de la consolidación de la modernización neoliberal autoritaria.

Para cerrar, quisiéramos señalar que, ello no obstante, y considerando la actual reactivación de los movimientos sociales y políticos opositores organizados en Chile, actualmente nos encontraríamos en un escenario de disputa ideológica y política interesante que podría (o no) indicar el inicio del término del ciclo neoliberal a nivel nacional, por lo menos, en su versión más radical. Esto si dicho escenario prospera y no es bloqueado por la élite financiera hegemónica, que tanto poder ha logrado acaparar desde la aplicación de la instauración y la consolidación de las recetas propias del establishment neoconservador en sus versiones tanto política (el llamado neoliberalismo) como académica (la teoría económica monetarista). Como señala Todorov, la democracia consiste en limitar el poder o, a decir de George Montbiot (2013): «Toda la estructura del pensamiento neoliberal es un fraude. Las demandas de los ultra ricos se han vestido de teoría económica sofisticada y se han aplicado independientemente de su resultado. El completo fracaso de este experimento [...] no es impedimento para que se repita. Esto no tiene nada que ver con la economía. Tiene absolutamente que ver con el poder».

\section{Referencias bibliográficas}

AxeLrod, Robert (1986). La evolución de la cooperación. Madrid: Alianza Editorial. Bowles, Samuel (2004). Microeconomics, behavior, institutions and evolution. Princeton, New Jersey: Princeton University Press.

Bowles, Samuel y Gintis, Herbert (2001). «¿Ha pasado de moda la igualdad?: El Homo reciprocans y el futuro de las políticas igualitarias». En: GARGARELLA, Roberto y Ovejero, Félix (eds.). Razones para el socialismo. Barcelona: Paidós.

CASASSAS, David (2010). La ciudad en llamas: La vigencia del republicanismo comercial de Adam Smith. Barcelona: Montesinos.

CASTEL, Robert (2010). El ascenso de las incertidumbres. Buenos Aires: FCE.

CASTEL, Robert et al. (2013). Individuación, precariedad, inseguridad: Desinstitucionalización del presente. Buenos Aires: Paidós.

Coleman, James S. (2011). Fundamentos de teoría social. Madrid: CIS.

Domènech, Antoni (2013a). «Socialismo: ¿De dónde vino? ¿Qué quiso? ¿Qué logró? ¿Qué puede seguir queriendo y logrando?». En: Bunge, Mario y GambetTA, Carlos (eds.). ¿Tiene porvenir el socialismo? Buenos Aires: EUDEBA.

Elster, Jon (1989). «Reflexiones sobre marxismo, funcionalismo y teoría de los juegos». En: Roemer, John (ed.). El marxismo, una perspectiva analítica. México, DF: FCE.

- (1995). Psicología politica. Barcelona: GEDISA. 
- (2010). La explicación del comportamiento social. Barcelona: GEDISA.

Francisco, Andrés de (2007). Ciudadania y democracia: Un enfoque republicano. Madrid: Los Libros de la Catarata.

Frohlich, Norman et al. (1991). «Liderazgo político y bienes colectivos». En: ColoMER, Josep (ed.). Lecturas de teoría política positiva. Madrid: Instituto de Estudios Fiscales.

Gárate, Manuel (2014). La revolución capitalista en Chile (1973-2003). Santiago de Chile: UAH.

García Sobrecases, Francisco (2000). Acción colectiva y bienes públicos: Una introducción al análisis no cooperativo. Valencia: Universidad de Valencia / Tirant Lo Blanch.

Gargarella, Roberto (1999). Las teorías de la justicia después de Rawls: Un breve manual de filosofía politica. Barcelona: Paidós.

- (2014). La sala de máquinas de la constitución. Buenos Aires: Katz.

Garretón, Manuel Antonio (2002). «La transformación de la acción colectiva en América Latina». Revista de la CEPAL, 76 (abril), 7-24.

Goodin, Robert (ed.) (2003). Teoría del diseño institucional. Barcelona: GEDISA.

Habermas, Jurgen y Rawls, John (1998). Debate sobre el liberalismo político. Barcelona: Paidós.

Hardin, Garrett (1968). "The tragedy of the commons». Science [en línea], 162 (3859), 1243-1248. <http://dx.doi.org/10.1126/science.162.3859.1243>.

Harvey, David (2003). El nuevo imperialismo. Madrid: Akal.

- (2007). Breve historia del neoliberalismo. Madrid: Akal.

KleIN, Naomy (2010). La doctrina del shock: El auge del capitalismo del desastre. Barcelona: Paidós.

Nozick, Robert (1988). Anarquía, estado y utopía. México, DF: FCE.

Ostrom, Elinor (2000). El gobierno de los bienes comunes: La evolución de las instituciones colectivas. México, DF: UNAM / CRIM / FCE.

Peters, B. Guy (2003). El nuevo institucionalismo: Teoría institucional en ciencia politica. Barcelona: GEDISA.

Pettit, Philip (2003). «Diseño institucional y elección racional». En: Goodin, Robert (ed.). Teoría del diseño institucional. Barcelona: GEDISA.

PiketTy, Thomas (2014). El capital en el siglo XXI. México, DF: FCE.

Pisarello, Gerardo (2011). Un largo Termidor. Madrid: Trotta.

Polanyi, Karl (2003). La gran transformación: Los orígenes politicos y económicos de nuestro tiempo. México: FCE.

PrZeworski, Adam (1987). «Marxismo y elección racional». Zona Abierta, 45, 97-136.

- (1989). "Intereses materiales, compromiso de clase y transición al socialismo». En: Roemer, John (ed.). El marxismo: una perspectiva analitica. México, DF: FCE.

- (1994). "Algunos problemas en el estudio de la transición hacia la democracia». En: O’Donnell, Guillermo; Schmitter, Philippe y Whitehead, Laurence (eds.). Transiciones desde un gobierno autoritario 3: Perspectivas comparadas. Barcelona: Paidós.

- (1995). Democracia y mercado: Reformas políticas y económicas en la Europa del Este y América Latina. Cambridge: Cambridge University Press.

- (2010). Qué esperar de la democracia: Límites y posibilidades del autogobierno. Buenos Aires: Siglo XXI Editores.

Schelling, Thomas C. (1989). Micromotivos y macroconductas. México, DF: FCE. 
Viera, Christian (2014). Libre iniciativa económica y estado social. Santiago de Chile: Thomson Reuters.

Vilas, Carlos (2000). «Más allá del Consenso de Washington?: Un enfoque desde la política de algunas propuestas del BM sobre reforma institucional». Revista del CLAD, Reforma y Democracia, 18.

Williamson, Oliver E. (2001). "La nueva economía institucional, balance y perspectivas». Revista Banco Central de Venezuela, XV (1), 6-34.

\section{Recursos electrónicos}

Castel, Robert (2013). «El individuo no puede existir sin soporte social». Viento Sur [en línea]. <http://vientosur.info/spip.php?article7814> [Consulta: abril 2015].

Cномsкy, Noam (2010). «Rabia mal dirigida». Sinpermiso [en línea]. <http://www. sinpermiso.info/textos/index.php?id=3720> [Consulta: mayo 2012].

Cowen, Tyler (s/a). Public Goods and Externalities [en línea]. <http://www.econlib. org/library/ENC/PublicGoodsandExternalities.html> [Consulta: enero 2016].

Domènech, Antoni (2006). "La globalización es la venganza del rentista. Entrevista». Sinpermiso [en línea]. <http://www.sinpermiso.info/textos/la-globalizacin-es-lavenganza-del-rentista-entrevista> [Consulta: febrero 2016].

- (2013b). «La humanidad es una sola, no un cúmulo de culturas cerradas». Sinpermiso [en línea]. <http://www.sinpermiso.info/textos/index.php?id=5579> [Consulta: febrero 2015].

Domènech, Antoni y Raventós, Daniel (2010). "Después de la utopía». Simpermiso [en línea]. <http://www.sinpermiso.info/textos/index.php?id=3685> [Consulta: mayo 2012].

Fundación SOL (2013). Minuta de empleo [en línea], 32 (enero-marzo). Santiago de Chile: Fundación SOL. <http://www.fundacionsol.cl/wp-content/ uploads/2013/05/Minuta-Empleo-EFM-13.pdf> [Consulta: mayo 2013].

Gálvez, Recaredo y Kremerman, Marco (2016). «A quién sirve el negocio de las AFP». El Mostrador [en línea]. <http://www.elmostrador.cl/noticias/pais/2016/07/18/aquien-sirve-el-negocio-de-las-afp/> [Consulta: julio 2016].

Hoexter, Michael (2013). "Qué es el "neoliberalismo": Teoría, práctica e ideologema». Sinpermiso [en línea]. <http://www.sinpermiso.info/articulos/ficheros/hoex. pdf> [Consulta: junio 2015].

KucINich, Dennis (2010). «En los EEUU tenemos una economía a punto de asfixiarse. Entrevista». Sinpermiso [en línea]. <http://www.sinpermiso.info/textos/index. php?id=3729> [Consulta: mayo 2015].

Kwame Sundaram, Jomo y Popov, Vladimir (2013). «La creciente desigualdad mundial de ingresos». Sinpermiso [en línea]. <http://www.sinpermiso.info/articulos/ ficheros/8biddesig.pdf> [Consulta: enero 2016].

McCarthy, Nancy (2004). «Bienes públicos y acción colectiva en el ámbito local». En: Acción colectiva y derechos de propiedad para el desarrollo sostenible [en línea]. <http:// ebrary.ifpri.org/cdm/ref/collection/p15738coll2/id/129320> [Consulta: abril 2015].

Моnтвіот, George (2013). «¿Está acabado el neoliberalismo?: Pensémoslo de nuevo». Sinpermiso [en línea]. <http://www.sinpermiso.info/textos/index.php?id=5618> [Consulta: enero 2016].

Rosen, David (2010). «Es hora de volver a llamar a la lucha de clases por su nombre». Sinpermiso [en línea]. <http://www.sinpermiso.info/textos/index.php?id=3679> [Consulta: mayo 2015]. 